\title{
FEEDBACK ANAL YSIS OF INTERACTION BETWEEN URBAN DENSITIES AND TRAVEL MODE SPLIT
}

\author{
Feng, X. ${ }^{*}$; ; Gan, T. ${ }^{*}$; Wang, X. ${ }^{*}$; Sun, Q. ${ }^{* *} \&$ Ma, F. ${ }^{* *}$ \\ *MOE Key Laboratory for Urban Transportation Complex Systems Theory and Technology, \\ Beijing Jiaotong University, China \\ ${ }^{* *}$ School of Economics and Management, Chang'an University, Xi'an, China \\ E-Mail: xsfeng@bjtu.edu.cn ( ${ }^{1}$ Corresponding author)
}

\begin{abstract}
A feedback simulation model based on radial basis function neural networks is newly developed in this research to analyse the interaction between urban densities and travel mode split. The changes of populations, road mileages, travel mode split, and so on of the enlarging urbanized areas of different cities in China are studied for the trainings of the radial basis function neural networks constituting the proposed feedback model. Furthermore, the effect of different development policies for Beijing on distinct indicators of the urban density and trip shares of various travel modes is also evaluated by the newly developed model. It is found that stopping the quick urban sprawl of Beijing is the most important for the sustainable development of its urban transport. It is confirmed that the newly developed model is able to rationally explain the interactive correlation between urban densities and travel mode split of a city for its different development plans.

(Received, processed and accepted by the Chinese Representative Office.)
\end{abstract}

Key Words: Urban Densities, Travel Mode Split, Radial Basis Function Neural Network, Feedback Simulation Modelling, Sustainable Urban Transport Development

\section{INTRODUCTION}

In the past decades, many cities especially in developing countries have experienced dramatic changes in both land use and transport $[1,2]$ which have been recognized to actively interact with each other [3-5], mainly owing to the power of urban economy [6]. The interaction between the systems of land use and transport is a dynamic process which involves changes over spatial and temporal dimensions between these two systems [7]. Understanding the interaction between land use and transport is critical for the urban and transport planning, especially in the case of a rapidly growing city with its quick urban motorization [8]. Till now, many efforts have been successively made to analyse the impacts of a wide range of factors on mediating the relationship between urban land use and transport, including settlement size, mix of land use, transport accessibility and so forth [9-14]. It has been proved that land use change can modify travel patterns to induce more changes in urban transport systems and, on the other hand, transport system evolution is able to create new accessibility levels that encourage changes in land use [10]. This interactive relationship is also referred to as the "land use transport feedback cycle" which can be described through some variables regarding geographical features and activity locations, demographic and economic characteristics, transport variables, and characteristics of urban mobility demands [7]. Different approaches and techniques such as cellular automata, structural equation modelling and geographic information systems have been applied to try to explain the nature of this feedback cycle in theory $[8,10,11]$.

Though valuable research findings are continually obtained, debates about urban form sustainability have always been increasing, focusing on shapes, sizes, densities, energy consumption and so on of cities, their correlations with travel patterns and the solutions for challenging urban sprawl and decentralization [15-20]. The urban land use characteristics of a city, such as the urban densities of its population, roads, etc., which are closely associated 
with the travel frequency [21], and their correlations with the travel behaviours of the trip makers in the urban area of the city still ought to be further analysed for the sustainable urban and transport development $[22,23]$. In particular, the dynamic feedback mechanism of the interaction between the densities of urban population, roads, rail lines, etc. and the shares of the urban trips completed by different travel modes need much more intensive studies. As a result, this research makes an attempt to develop a new feedback model from an integrated perspective to dynamically simulate the continual interaction between the urban densities and travel mode split of a city.

In order to clarify the interrelation between the densities of urban population, buildings, roads, etc. and the choice ratios of various travel patterns, functions which are capable of properly explaining the corresponding nonlinear mappings in input-output pairs of data are indispensable especially for the dynamic feedback analysis. One widely applied approach to seek such a function is approximation which can be achieved by either parametric or nonparametric statistical procedures $[24,25]$. In contrast to parametric analyses relying on the assumptions about the shape or form of the underlying population distribution, nonparametric studies make fewer assumptions about the distribution of measurements in the same population [24, 25], and therefore, have been more and more extensively applied especially in recent years. Furthermore, as a nonparametric approach, an artificial neural network can be considered as a universal approximator [26] and it possesses the self-learning capability [27]. Therefore, the complexity of seeking the rational functions can be reduced by constructing and learning the nonlinear mappings through the neural network trainings with examples. However, the approximations to the learning situations by conventional neural networks often lead to very high-dimensional interpolation problems with scattered data [28]. Consequently, radial basis function (RBF) neural networks [27, 29] have been put forward to solve such issues. Owing to its faster learning capability compared with other feedforward networks [27] as well as its ability of solving the high-dimensional interpolation problems [29], a RBF neural network is usually regarded as a good candidate for an approximation problem.

As a result, RBF neural networks are used as the foundations of the newly developed feedback model in this study. In other words, the iterative feedbacks between different trained RBF neural networks which are utilized in the new model to explain the effect of the urban densities on travel mode split or that in reverse never stop until the outputs of all these RBF neural networks become stable. In this way, the dynamic feedback mechanism of the interaction between the urban densities and the travel mode split is interpreted by the proposed model in simulation from the perspective of integrating the artificial neural network analysis and the feedback modelling study. In addition, the officially released annual statistical data about the urban areas, populations, roads, etc. of different cities in China are used as the examples to train the RBF neural networks applied in the newly developed model in this research.

The remaining parts of this paper are organized as follows. As the base data of the feedback modelling work in this research, the annual statistical data for different cities in China are introduced in Section 2. Next, Section 3 develops the new feedback simulation model based on the RBF neural networks. Thereafter, the impacts of various policies on the interaction between the urban densities and the travel mode split in a study area are analysed in comparison in Section 4. Finally, Section 5 provides the conclusions of this research and discusses some future research issues.

\section{DATA COLLECTION}

As the biggest three megacities in China, Beijing, Shanghai and Guangzhou all have not only obtained quick urban growths but also increased evidently in motorization in the past 
approximately 30 years. Such changes are clearly demonstrated by the rapid increases of the urbanized areas and the road mileages shown in Fig. 1 and Fig. 2, respectively. It is indicated in Fig. 1 that the urban areas of Shanghai and Guangzhou have both increased by about 5 times from around 200 square kilometres $\left(\mathrm{km}^{2}\right)$ to about $1,000 \mathrm{~km}^{2}$ from the end of $1980 \mathrm{~s}$ to the beginning of 2000s. By contrast, though the area of the urbanized region of Beijing has increased by only approximately 3 times, the urbanized area has increased to about $1800 \mathrm{~km}^{2}$ in 2012 from originally around $600 \mathrm{~km}^{2}$ in 1989. Moreover, as presented in Fig. 2, during the same time period, the mileages of the roads in the urban regions of Beijing, Shanghai and Guangzhou have increased from approximately $1,500 \mathrm{~km}, 1,600 \mathrm{~km}$ and $800 \mathrm{~km}$ to correspondingly about $8,000 \mathrm{~km}, 4,900 \mathrm{~km}$ and $7,000 \mathrm{~km}$. In other words, the increases are more than 5 times, over 3 times and nearly 9 times, respectively. Moreover, it is also noticed in Fig. 1 and Fig. 2 that both the area of the urbanized region and the total mileage of all the urban roads of Guangzhou have obtained significant increases from 2000 to 2001.

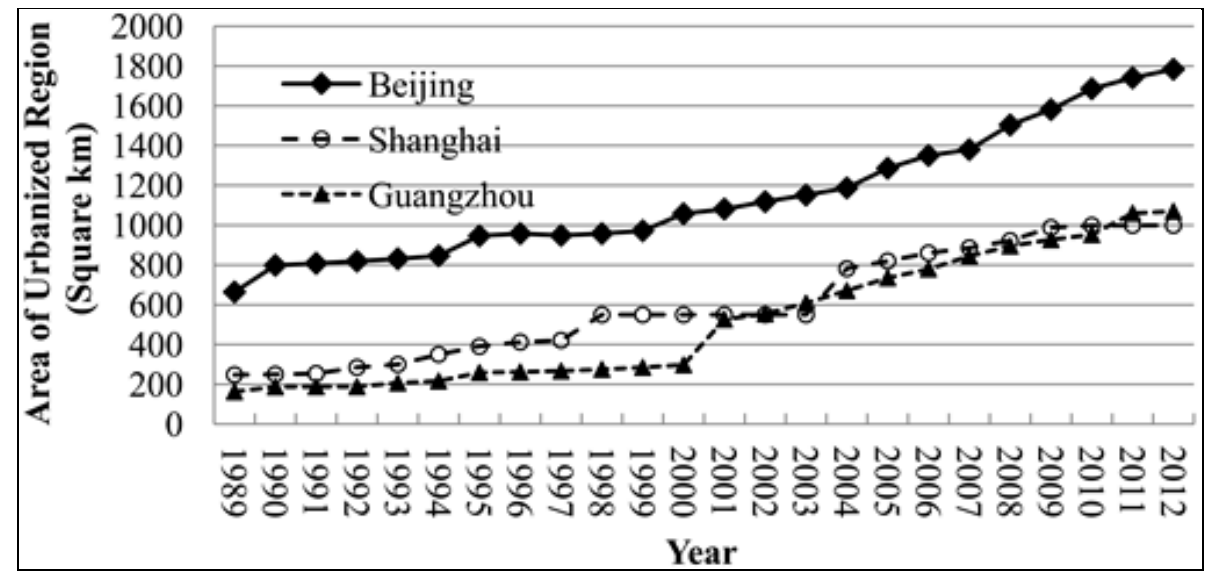

Figure 1: Changes of the areas of the urbanized regions in different cities.

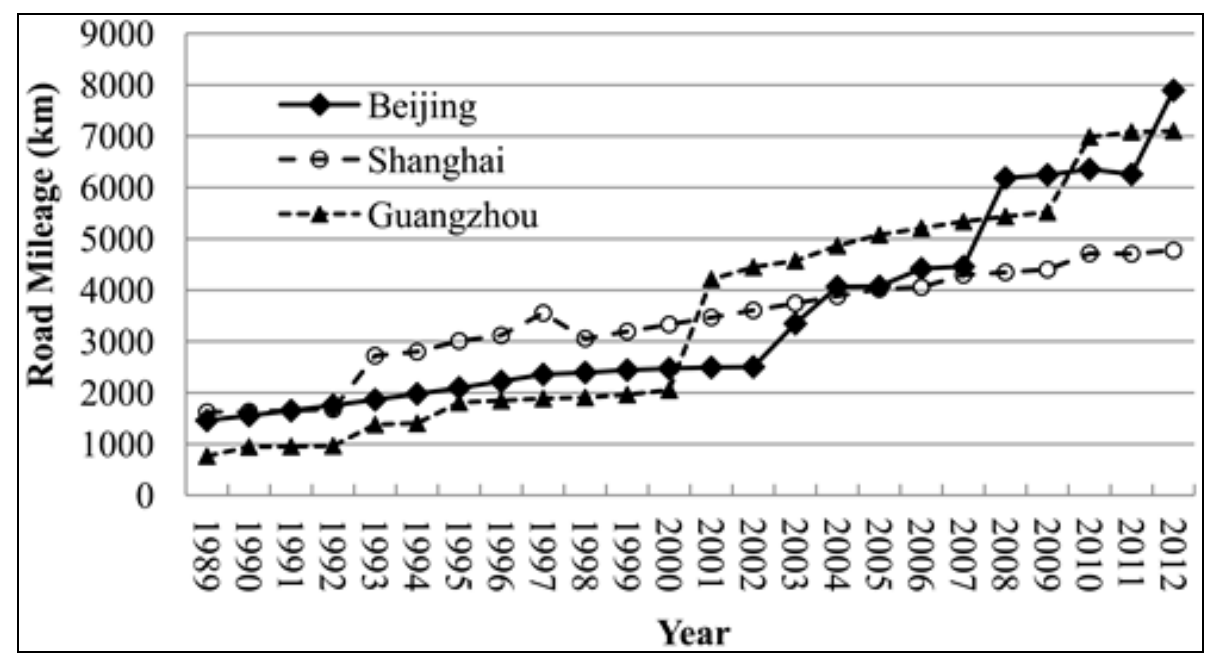

Figure 2: Changes of the road mileages of the urbanized regions in different cities.

In this research, the increases of the areas, populations, road mileages and rail mileages of the urbanized regions in Beijing, Shanghai and Guangzhou and the changes of the trip shares of various travel modes taken by the residents in the urban areas of these three megacities have been investigated according to the data officially released annually in the statistical yearbooks published from 1990 to 2013 for these cities. The missing values of some of the statistical data for certain years are estimated based on the tendencies revealed by the existing data. Accordingly, it is able to model in the next step the feedback correlation between the 
densities of the populations, roads and rail lines in the urbanized regions of these three cities and the travel mode split in the same areas. Fig. 3 illustrates the changes of the proportions of the trips made by bus in the urban areas of Beijing, Shanghai and Guangzhou. It is clearly shown that the shares of the bus trips in the urban areas of Beijing and Guangzhou have both been generally increasing from 1989 to 2012 while the ratio of the trips by bus in the urbanized region of Shanghai has, on the contrary, obtained an overall decrease in the same years.

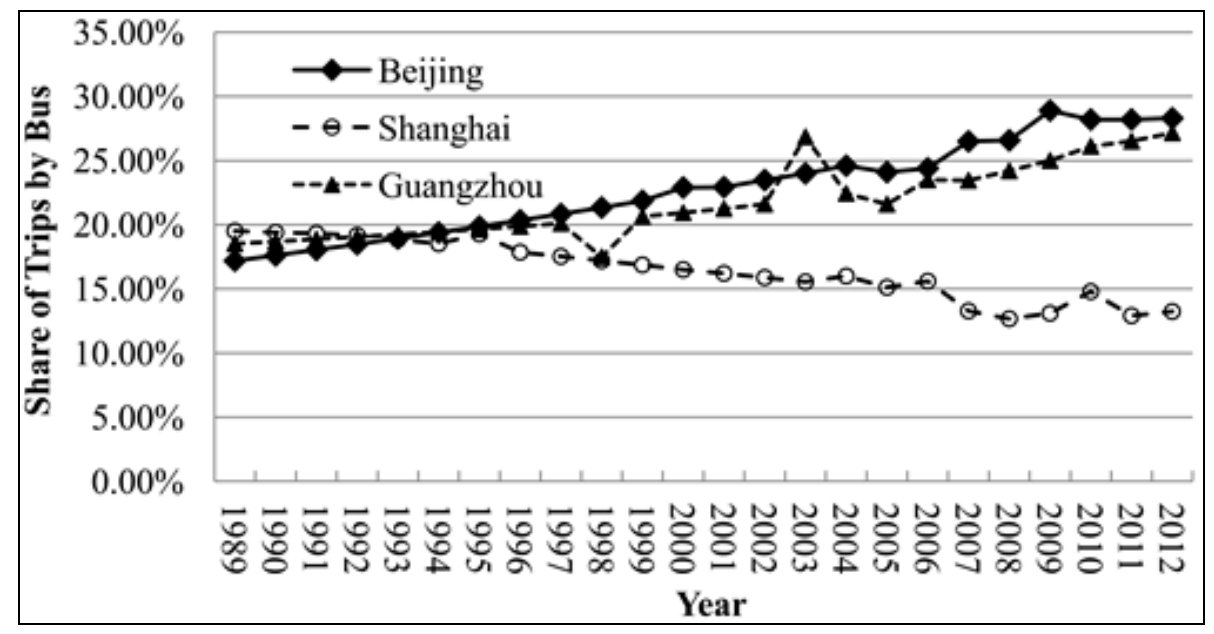

Figure 3: Changes of the shares of the bus trips in the urbanized regions of different cities.

\section{MODELLING STUDY}

In a conventional RBF neural network whose basic architecture is explained in Fig. 4, the Gaussian function and the least squares (LS) criterion are usually used as the activation function and the objective function, respectively [27, 30, 31]. The RBF for a neuron in the hidden layer of the neural network has a centre and a radius which is also called a spread. With a larger spread, a neuron at a certain distance from a point has a greater influence. Each hidden neuron represents the Gaussian activation function and computes the distance between the input vector pattern and the centres to determine the weights from the hidden layer to the output layer. The parameters of a neuron are adjusted iteratively by minimizing the LS criterion.

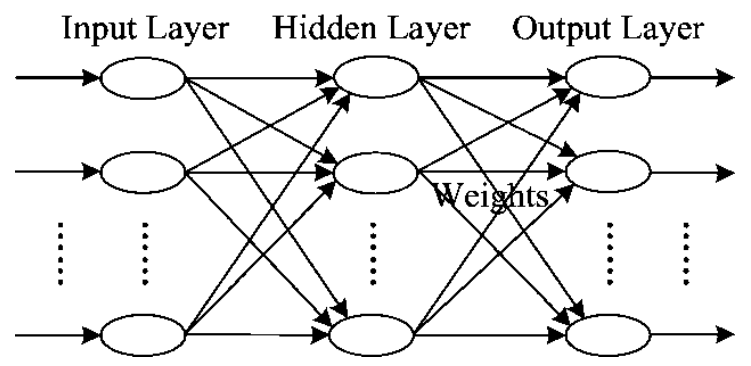

Figure 4: Basic architecture of a traditional RBF neural network.

Similar to the architecture of a general RBF neural network, the architecture of combined RBF neural networks with the same input layer but different hidden layers is provided in Fig. 5. It is indicated in this figure that the elements of the input layer can be divided into various sets from I1 to II. Moreover, different hidden layers are represented by the variables from $\mathrm{h} 1$ to hJ. In addition, distinct sets of outputs from $\mathrm{O} 1$ to $\mathrm{OJ}$ result from the work of corresponding hidden layers through the respective sets of weights from hwl to hwJ. Such 
architecture makes it possible to establish a feedback loop by adding another set of hidden layers from the outputs to the inputs at present. In this way, all the current outputs constitute the new input layer. The newly added hidden layers are responsible to make respective estimations in correspondence to different sets of the elements in the old input layer.

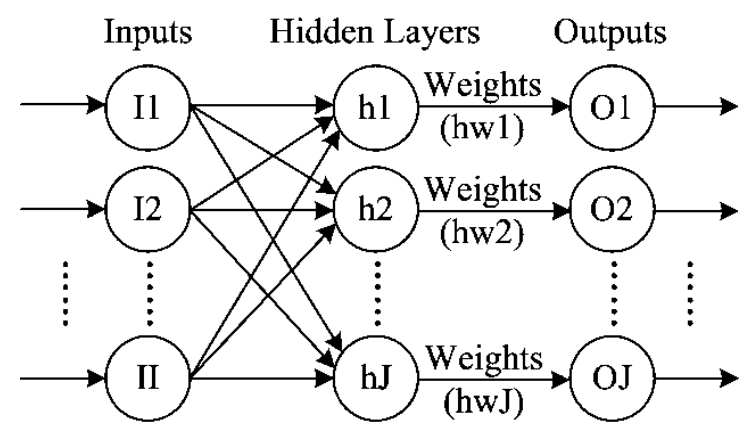

Figure 5: Architecture of combined RBF neural networks.

If the urban densities compose the same set of the inputs to each of different RBF neural networks and the share of the trips by a certain travel mode is the output of one of these RBF neural networks, the feedback loop can be formed when each urban density indicator is the output of one of the RBF neural networks taking the travel mode split as their common input. In this work, all the utilized RBF neural networks are trained according to the previously explained annual statistical data of the areas, populations, road mileages, rail mileages and shares of trips by different travel modes for the urbanized regions of Beijing, Shanghai and Guangzhou. The loop between different sets of the trained RBF neural networks which either take urban density indicators as their inputs and output the trip shares by different travel modes or have the converse inputs and outputs is used in this work to establish a new feedback model for the simulation of the interaction between various urban densities and travel mode split.

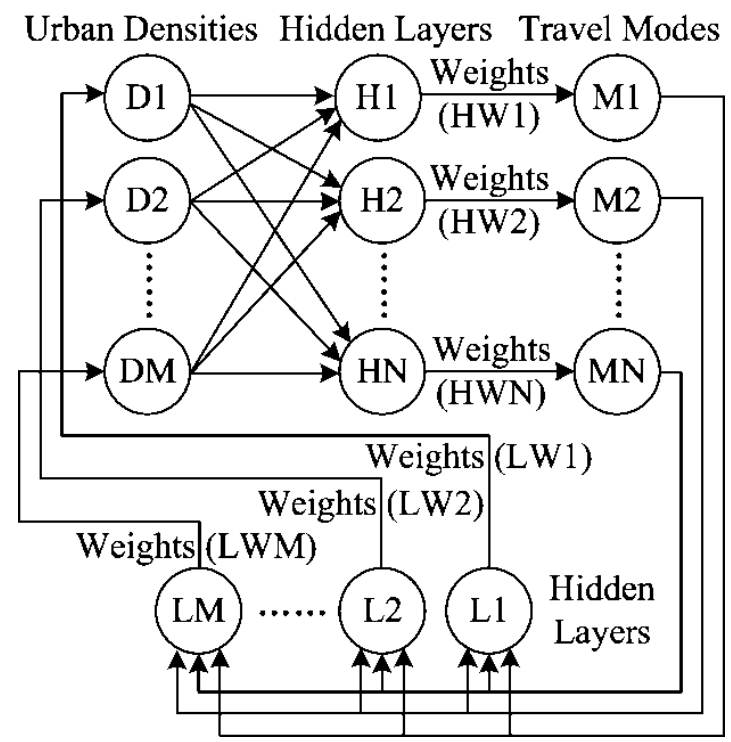

Figure 6: Framework of the proposed feedback model based on RBF neural networks.

Fig. 6 presents the framework of the new feedback simulation model developed in this study. DM and $\mathrm{MN}$ in this figure stand for the $M^{\text {th }}$ indicator of the urban density and the trip share of the $N^{\text {th }}$ travel mode, respectively. Moreover, the $N^{\text {th }}$ hidden layer from the urban densities to the share of the trips by the $N^{\text {th }}$ travel mode through the weights HWN and the $M^{\text {th }}$ hidden layer from the travel mode split to the $M^{\text {th }}$ urban density through the weights LWM are 
correspondingly represented by $\mathrm{HN}$ and LM. There are totally $(N+M)$ RBF neural networks which are first of all trained by the previously explained annual statistical data and thereafter included into the iterative feedback simulation process of the newly developed model in this research. In general, the continuing interaction between the urban densities and the travel mode split is iteratively simulated until the difference of the outputs of each included RBF neural network in its successive iterations become small enough to meet certain convergence criteria.

In this work, the iteratively feedback simulative evaluations on the effect of the interaction between urban densities and travel mode split on their changes under the influence of a certain measure for the urban and transport development stop when the following convergence criterion is met:

$$
\operatorname{Max}(M D)=\operatorname{Max}\left\{\frac{\left|M_{i+1}^{k}-M_{i}^{k}\right|}{M_{i}^{k}}, \frac{\left|D_{i+1}^{l}-D_{i}^{l}\right|}{D_{i}^{l}}\right\}<\varepsilon
$$

where $M_{i}^{k}$ denates the evaluated share of the trips by the $k^{\text {th }}$ travel mode in the $i^{\text {th }}$ iterative simulation, $D_{i}^{l}$ is the evaluated density of the $l^{\text {th }}$ index in the $i^{\text {th }}$ iteration, and $\varepsilon$ represents a small positive number which is set to be 0.10 in this work.

\section{CASE ANALYSIS}

In this research, the interaction between the densities of population, roads and rail lines in the urbanized area of Beijing and the shares of the trips by different travel modes in the same urban region is studied by the newly developed feedback model for different cases with distinct development policies applied for five years. Each of the RBF neural networks used to establish the new model has its own test error smaller than $5.00 \%$ after its training process. The contents of different cases are explained as follows.

Case 1: Follow current trends; do nothing option. All the changes (e.g., the annual increases of urbanized area and population) keep their present tendencies.

Case 2: Encourage trips by public travel modes. $20.00 \%$ of the car trips today are shift to bus and rail evenly; the other tendencies are the same with those in Case 1.

Case 3: Decelerate urban sprawl. The annual increase of the urbanized area slows down by $20.00 \%$ while the other trends are the same with those in Case 1.

The purpose of Case 1 in this study is to find out what will happen if we continue our actions at this time. Case 2 and Case 3 try to explore the effect of taking additional efforts to change the travel pattern choices of trip makers at present and the current densities of urban land uses respectively on the improvement of sustainable urban and transport development of Beijing.

Fig. 7 provides the application procedure of the newly developed feedback model with the new initial inputs according to the details of different policies applied in various cases for the predictive analyses of the urban densities and the travel mode split. The iteratively simulative evaluations on the influence of the interaction between the densities of urban population, roads, etc. and the trip shares of different travel modes upon the changes of the densities and the trip shares continue if the iteration has been made for only once or has not been converged, as illustrated in Fig. 7. Before the start of a new iteration, the urban densities outputted from some of the RBF neural networks utilised in the newly proposed feedback model are taken as the inputs of the other RBF neural networks used in this new model. Meanwhile, the other RBF neural networks output the travel mode split which is inputted into the RBF neural networks output the urban densities. This is the exact meaning of the "Take Outputs as the Inputs" shown in Fig. 7. 


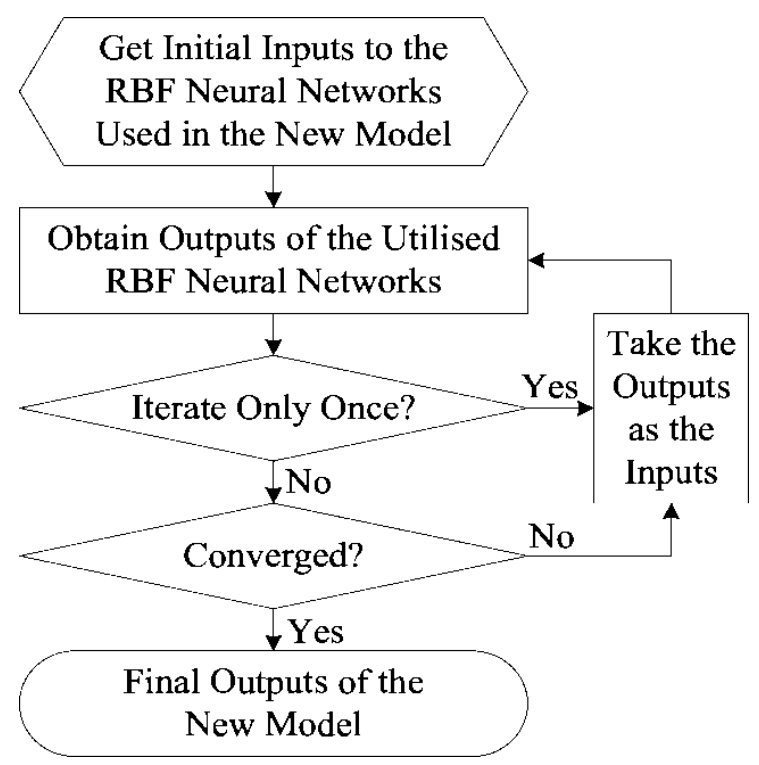

Figure 7: Application procedure of the newly developed model.

The convergence processes of the iteratively simulative evaluations by the proposed model on the interaction between urban density and land use are shown in Fig. 8 for different cases. The vertical and horizontal axes in this figure represent the $\operatorname{Max}(M D)$ explained in Section 3 and the number of the iterations, respectively. It is obvious that the $\operatorname{Max}(M D)$ of the simulative evaluation for each case decreases very quickly in the first several iterative analyses. Thereafter, though the decreases for each of the cases becomes apparently slower, the previously determined convergence criterion (i.e., 0.10) in this research still can be steadily reached within certain iterations. With the iterative evaluation process converged, the outputs of the model application become stable. Such outputs are able to rationally reveal the changes of the dynamically interactive urban density and travel modal split under the influence of applying certain urban and transport policies.

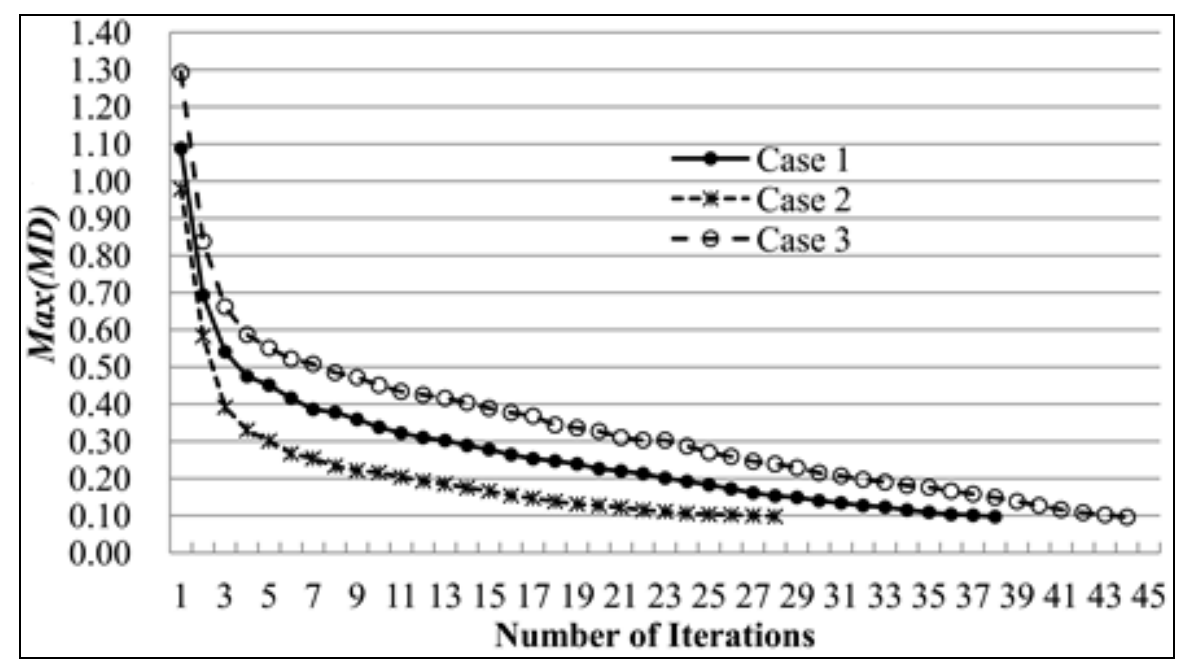

Figure 8: The convergence processes of the iterative evaluations.

Table I presents not only the predicted values of various indicators of the urban density and the shares of the trips by different travel modes in the urban area of Beijing for different cases after the convergences of the iteratively simulative evaluations on the interaction between the urban densities and the travel mode split but also the current values of the same variables. It is shown in this table that if all the changes in the urbanized region of Beijing 
keep their current tendencies (i.e., Case 1), in comparison to the values of the same variables at present, the densities of the population and the rail lines in this area will both be mildly decreased after five years while the density of roads in the same region will obviously increase. As a result, more people are going to make their trips by bus because of less traffic congestions owing to the rapid increase of the roads in a relatively short time period. Nevertheless, it is also revealed in Table I that the car trips induced by the quick increase of the road density will be evidently increased at the same time. Furthermore, the share of the rail trips will be reduced due to the decrease of the density of rail lines, and the ratio of the trips by taxi will also decrease because of the increases of the trips by car and bus.

Table I: Changes of the values of distinct variables for various cases.

\begin{tabular}{|c|c|c|c|c|c|c|c|}
\hline Variables & $\begin{array}{c}\text { Density of } \\
\text { population } \\
\left(1,000 \text { people } / \mathrm{km}^{2}\right)\end{array}$ & $\begin{array}{c}\text { Density } \\
\text { of roads } \\
\left(\mathrm{km} / \mathrm{km}^{2}\right)\end{array}$ & $\begin{array}{c}\text { Density of } \\
\text { rail lines } \\
\left(\mathrm{km} / \mathrm{km}^{2}\right)\end{array}$ & $\begin{array}{c}\text { Car trip } \\
\text { share } \\
(\%)\end{array}$ & $\begin{array}{c}\text { Bus trip } \\
\text { share } \\
(\%)\end{array}$ & $\begin{array}{c}\text { Rail trip } \\
\text { share } \\
(\%)\end{array}$ & $\begin{array}{c}\text { Taxi trip } \\
\text { share } \\
(\%)\end{array}$ \\
\hline $\begin{array}{c}\text { Current } \\
\text { values }\end{array}$ & 14.10 & 6.26 & 0.35 & 38.67 & 33.57 & 19.93 & 7.83 \\
\hline Case 1 & 12.90 & 12.59 & 0.34 & 41.35 & 36.69 & 16.43 & 5.53 \\
\hline Case 2 & 12.91 & 12.60 & 0.34 & 37.46 & 38.89 & 18.21 & 5.44 \\
\hline Case 3 & 13.46 & 12.99 & 0.36 & 34.34 & 37.76 & 23.31 & 4.59 \\
\hline
\end{tabular}

In contrast, if people are encouraged to make their trips by bus and rail (i.e., Case 2), the share of the trips by car in the near future will, in fact, not be reduced as desired in comparison to its current value, as indicated in Table I. This is because of not only the low densities of the population and rail lines but also the high density of the roads, though some policies applied to improve public transport priority will, in some degree, increase the densities of the population and roads in the urbanized area. However, if the sprawl of the urbanized area of Beijing can be sufficiently decelerated (i.e., Case 3), obviously more percentage of the trips by car will be successfully transferred to both bus and rail. Therefore, though successfully controlling the urban sprawl of Beijing is not easy [32, 33], it is crucial at this time to stop the quick sprawl of the urbanized region of Beijing for the sustainable development of its urban transport. This has also been suggested by some studies (e.g., the work of Zhao [34]) from different perspectives.

\section{CONCLUSIONS}

In view of their abilities of fast learning and efficiently solving high-dimensional interpolation problems, RBF neural networks are used in this work to newly develop a feedback simulation model with combining the artificial neural network analysis and feedback modelling study to analyse the interactive correlation between urban densities and travel mode split. All the RBF neural networks utilized in this research are trained based on the annual statistical data about the urban densities and trip shares of different travel modes for different Chinese cities. Various policies have also been comparatively studied by the proposed model to explain the effect of the interaction between urban densities and travel mode split on the sustainable urban and transport development of Beijing for its different development scenarios. It is confirmed that the newly developed feedback simulation model is capable of rationally interpreting the interactive relationship between urban densities and travel mode split.

In this study, only the annual statistical data from three megacities in China have been used for the trainings of the RBF neural networks which are applied to establish the feedback model. Various kinds of data from more types of cities in different countries in the world ought to be collected and utilized in future work to improve the validity and applicability of the proposed model. In addition, both the suitability of generalization capability of a RBF 
neural network and the appropriateness of its robustness are also very necessary to be analysed in the future for the proposed feedback simulation model in consideration of the characteristics of specific urban and transport issues.

\section{ACKNOWLEDGEMENTS}

This research is supported by the Program for New Century Excellent Talents in University (NCET13-0655) and the National Natural Science Foundation of China (71201006; 71390332).

\section{REFERENCES}

[1] Aljoufie, M.; Zuidgeest, M.; Brussel, M.; van Maarseveen, M. (2013). Spatial-temporal analysis of urban growth and transportation in Jeddah City, Saudi Arabia, Cities, Vol. 31, 57-68, doi: $10.1016 /$ j.cities.2012.04.008

[2] Mendiola, L.; González, P.; Cebollada, À. (2014). The link between urban development and the modal split in commuting: The case of Biscay, Journal of Transport Geography, Vol. 37, 1-9, doi:10.1016/j.jtrangeo.2014.03.014

[3] Zondag, B.; de Bok, M.; Geurs, K. T; Molenwijk, E. (2015). Accessibility modeling and evaluation: The TIGRIS XL land-use and transport interaction model for the Netherlands, Computers, Environment and Urban Systems, Vol. 49, 115-125, doi:10.1016/j.compenvurbsys. 2014.06.001

[4] Liu, L.; Alain, L. (2014). Transport and land use interaction: A French case of suburban development in the Lille Metropolitan Area (LMA), Transportation Research Procedia, Vol. 4, 120-139, doi:10.1016/j.trpro.2014.11.011

[5] Wegener, M. (2013). Land-use transport interaction models, Fischer, M. M.; Nijkamp, P. (Eds.), Handbook of Regional Science, Springer-Verlag, Heidelberg, 741-758

[6] Frank, L. D. (2004). Economic determinants of urban form: Resulting trade-offs between active and sedentary forms of travel, American Journal of Preventive Medicine, Vol. 27, No. 3, Supplement, 146-153, doi:10.1016/j.amepre.2004.06.018

[7] Eboli, L.; Forciniti, C.; Mazzulla, G. (2012). Exploring land use and transport interaction through structural equation modelling, Procedia - Social and Behavioral Sciences, Vol. 54, 107-116, doi:10.1016/j.sbspro.2012.09.730

[8] Aljoufie, M.; Zuidgeest, M.; Brussel, M.; van Vliet, J.; van Maarseveen, M. (2013) A cellular automata-based land use and transport interaction model applied to Jeddah, Saudi Arabia, Landscape and Urban Planning, Vol. 112, 89-99, doi:10.1016/j.landurbplan.2013.01.003

[9] Dieleman, F. M.; Dijst, M.; Burghouwt, G. (2002). Urban form and travel behaviour: Micro-level household attributes and residential context, Urban Studies, Vol. 39, No. 3, 507-527, doi: $10.1080 / 00420980220112801$

[10] Shaw, S.-L.; Xin, X. (2003). Integrated land use and transportation interaction: a temporal GIS exploratory data analysis approach, Journal of Transport Geography, Vol. 11, No. 2, 103-115, doi: 10.1016/S0966-6923(02)00070-4

[11] Cao, X.; Mokhtarian, P. L.; Handy, S. L. (2007). Do changes in neighborhood characteristics lead to changes in travel behavior? A structural equations modelling approach, Transportation, Vol. 34, No. 5, 535-556, doi:10.1007/s11116-007-9132-x

[12] Curtis, C. (2008). Planning for sustainable accessibility: The implementation challenge, Transport Policy, Vol. 15, No. 2, 104-112, doi:10.1016/j.tranpol.2007.10.003

[13] Maat, K.; Timmermans, H. J. P. (2009). A causal model relating urban form with daily travel distance through activity/travel decisions, Transportation Planning and Technology, Vol. 32, No. 2, 115-134, doi:10.1080/03081060902861285

[14] Ewing, R.; Greenwald, M.; Zhang, M.; Walters, J.; Feldman, M.; Cervero, R.; Frank, L.; Thomas, J. (2011). Traffic generated by mixed-use developments - six-region study using consistent built environmental measures, Journal of Urban Planning and Development, Vol. 137, No. 3, 248261, doi:10.1061/(ASCE)UP.1943-5444.0000068 
[15] Sadownik, B.; Jaccard, M. (2001). Sustainable energy and urban form in China: the relevance of community energy management, Energy Policy, Vol. 29, No. 1, 55-65, doi:10.1016/S0301$\underline{4215(00) 00105-1}$

[16] Mindali, O.; Raveh, A.; Salomon, I. (2004). Urban density and energy consumption: a new look at old statistics, Transportation Research Part A: Policy and Practice, Vol. 38, No. 2, 143-162, doi:10.1016/j.tra.2003.10.004

[17] Neuman, M. (2005). The compact city fallacy, Journal of Planning Education and Research, Vol. 25, No. 1, 11-26, doi:10.1177/0739456X04270466

[18] Buchanan, N.; Barnett, R.; Kingham, S.; Johnston, D. (2006). The effect of urban growth on commuting patterns in Christchurch, New Zealand, Journal of Transport Geography, Vol. 14, No. 5, 342-354, doi:10.1016/j.jtrangeo.2005.10.008

[19] Alqhatani, M.; Bajwaa, S.; Setunge, S. (2012). Land-use transport interaction: A comparison of Melbourne, Riyadh, Procedia - Social and Behavioral Sciences, Vol. 43, 3-13, doi:10.1016/ j.sbspro.2012.04.072

[20] Aguiléra, A.; Voisin, M. (2014). Urban form, commuting patterns and $\mathrm{CO}_{2}$ emissions: What differences between the municipality's residents and its jobs?, Transportation Research Part A: Policy and Practice, Vol. 69, 243-251, doi:10.1016/j.tra.2014.07.012

[21] Ma, J.; Mitchell, G.; Heppenstall, A. (2014). Daily travel behaviour in Beijing, China: An analysis of workers' trip chains, and the role of socio-demographics and urban form, Habitat International, Vol. 43, 263-273, doi:10.1016/j.habitatint.2014.04.008

[22] Banister, D. (2008). The sustainable mobility paradigm, Transport Policy, Vol. 15, No. 2, 73-80, doi:10.1016/j.tranpol.2007.10.005

[23] Aditjandra, P. T. (2013). The impact of urban development patterns on travel behaviour: Lessons learned from a British metropolitan region using macro-analysis and micro-analysis in addressing the sustainability agenda, Research in Transportation Business \& Management, Vol. 7, 69-80, doi: $10.1016 /$ j.rtbm.2013.03.008

[24] Brett, M.; Penny, W.; Kiebel, S. (2007). Chapter 17 - Parametric procedures, Friston, K.; Ashburner, J.; Kiebel, S.; Nichols, T.; Penny, W. (Eds.), Statistical Parametric Mapping, Elsevier/Academic Press, London, 223-231

[25] Conover, W. J. (1999). Practical Nonparametric Statistics, $3^{\text {rd }}$ edition, John Wiley \& Sons, Inc., New York

[26] Poggio, T.; Girosi, F. (1990). Network for approximation and learning, Proceedings of the IEEE, Vol. 78, No. 9, 1481-1496, doi:10.1109/5.58326

[27] Lee, C.-C.; Chung, P.-C.; Tsai, J.-R.; Chang, C.-I. (1999). Robust radial basis function neural networks, IEEE Transactions on Systems, Man, and Cybernetics, Part B: Cybernetics, Vol. 29, No. 6, 674-685, doi: $10.1109 / 3477.809023$

[28] Buhmann, M. D. (2003). Radial Basis Functions: Theory and Implementations, Cambridge University Press, Cambridge

[29] Saha, A.; Wu, C.-L.; Tang, D.-S. (1993). Approximation, dimension reduction, and nonconvex optimization using linear superpositions of Gaussians, IEEE Transactions on Computers, Vol. 42, No. 10, 1222-1233, doi:10.1109/12.257708

[30] Billings, S. A.; Wei, H.-L.; Balikhin, M. A. (2007). Generalized multiscale radial basis function networks, Neural Networks, Vol. 20, No. 10, 1081-1094, doi:10.1016/j.neunet.2007.09.017

[31] Yee, P. V.; Haykin, S. (2001). Regularized Radial Basis Function Networks: Theory and Applications, John Wiley \& Sons, Inc., New York

[32] Yang, J.; Zhou, J. (2007). The failure and success of greenbelt program in Beijing, Urban Forestry \& Urban Greening, Vol. 6, No. 4, 287-296, doi:10.1016/j.ufug.2007.02.001

[33] Zhao, P.; Lü, B.; Woltjer, J. (2009) Conflicts in urban fringe in the transformation era: An examination of performance of the metropolitan growth management in Beijing, Habitat International, Vol. 33, No. 4, 347-356, doi:10.1016/j.habitatint.2008.08.007

[34] Zhao, P. (2010). Sustainable urban expansion and transportation in a growing megacity: Consequences of urban sprawl for mobility on the urban fringe of Beijing, Habitat International, Vol. 34, No. 2, 236-243, doi:10.1016/j.habitatint.2009.09.008 